\title{
CONSCIÊNCIA HISTÓRICA, IDENTIDADES E ENSINO DE HISTÓRIA EM ESCOLAS NO MEIO RURAL BRASILEIRO
}

\section{HISTORICAL CONSCIOUSNESS, IDENTITIES AND HISTORY TEACHING IN BRAZILIAN RURAL SCHOOLS}

\author{
Astrogildo Fernandes Silva Junior (PG-UFU)*
}

Resumo: Este texto tem como objetivo compreender como os Parâmetros Curriculares Nacionais - PCN-, do ensino de História e as Diretrizes Operacionais da Educação Básica em Escolas do Campo podem contribuir para a formação da consciência histórica e das identidades dos jovens estudantes e dos professores de História no meio rural brasileiro. A metodologia utilizada foi uma pesquisa documental dialogando com referenciais teóricos que discutem consciência histórica, identidades e ensino de História. Concluiu-se que os PCN trazem um avanço considerável nas finalidades do ensino de História. A possibilidade de levar aos alunos à passagem de uma consciência histórica tradicional e exemplar para uma consciência história crítica e genética está dada nos documentos. Contudo não são suficientes para que se efetivem na prática.

Palavras-chave: Consciência histórica. Identidades. Ensino de História.

Abstract: This text has the objective to understand how the Parâmetros Curriculares Nacionais - PCN, of the History teaching and the Diretrizes Operacionais da Educação Básica em escolas do Campo can contribute to the formation of the historical consciousness and the identities from youth students and from History teachers in the brazilian rural area. The methodology used was the documental research linking with "theoretical" references who discuss historical consciousness, identity and history teaching. Taking together it was concludes that PCNs bring considerable advances in history teaching. The possibility to make the transition from a traditional and exemplar historical consciousness to a critics an genetics one is contemplated in the documents. However, the are not sufficient to be effective in practices.

Keywords: Historical Consciousness. Identities. History Teaching.

\section{Introdução}

O trabalho como professores e pesquisadores do ensino de História, na educação básica, vem, nos últimos anos, instigando-nos a pesquisar sobre a consciência histórica e as identidades de jovens estudantes e de professores de História em escolas no meio rural brasileiro. Nesse percurso, algumas questões tornaram-se recorrentes: o que é consciência histórica? Qual a relação entre consciência histórica e identidades? Os saberes históricos escolares influenciam a consciência histórica e as identidades dos estudantes e dos professores de História? Qual a proposta curricular do ensino de História nos anos finais do ensino fundamental, na realidade específica, que é o meio

\footnotetext{
* Doutorando no Programa de Pós-Graduação em Educação da Universidade Federal de Uberlândia; bolsista Capes.
} 
rural? Como essa proposta pode influenciar na consciência histórica e nas identidades dos sujeitos envolvidos, ou seja, alunos e professores?

Segundo Pagés e Santisteban (2008), o século XXI é caracterizado por uma série de mudanças, é um tempo marcado por incertezas e riscos, porém o ensino de História parece não ter mudado muito. Os jovens, quando terminam a educação obrigatória, acumulam uma grande quantidade de informações em forma de fatos, personagens e instituições isoladas, sem conexão e organizada em um tempo descontínuo. $\mathrm{O}$ autor destaca a importância da temporalidade na história, ajudando a formar a consciência histórica.

É importante ressaltar que a formação histórica dos estudantes depende apenas em parte da escola, cada vez mais o papel dos meios de comunicação de massa, da família e do meio imediato em que o aluno vive, interfere na consciência histórica dos estudantes. Porém, nos limites deste texto, temos como objetivo compreender como os Parâmetros Curriculares Nacionais $-\mathrm{PCN}^{\dagger}$-, do ensino de História e as Diretrizes Operacionais da Educação do Campo podem contribuir para a formação da consciência histórica e das identidades dos jovens estudantes e dos professores de História no meio rural brasileiro. Como referencial teórico, fundamentamo-nos nos estudos de Rusen (1999 e 2001), Heller (1992 e 2007), Pais (1999), Zamboni (2003), Schmidt e Garcia (2005), Cerri (2001), Páges e Santisteban (2008), Hall (2005), Bauman (2005), Lévy (2007), Fonseca (2001 e 2005) e Bittencourt (2004).

No desenvolvimento deste estudo, consideramos importante reportar, historicamente, a qual era a finalidade da História como disciplina escolar. Dessa forma, o trabalho foi organizado em quatro partes. Na primeira, fizemos uma revisão teórica sobre consciência histórica. Na segunda, descrevemos, de maneira breve, o histórico do ensino de História no Brasil. Na terceira parte, apresentamos os PCN e as Diretrizes Operacionais da Educação do Campo e procuramos fazer uma relação dos conteúdos com a formação da consciência histórica e das identidades de alunos e professores. Por fim, nossas considerações.

\section{Consciência histórica: uma revisão teórica}

Antes de iniciar a discussão teórica sobre consciência histórica, retomamos Cerri (2001), quando assevera que esse conceito reforça a tese de que a história, na escola, é um tipo de conhecimento histórico qualitativamente diferente do conhecimento produzido por especialistas acadêmicos. Segundo o autor,

\footnotetext{
† De acordo com Governo Federal, os PCN, lançados em 1997, são um conjunto de orientações para melhorar a qualidade do ensino e de contribuir para a formação de cidadãos mais conscientes, críticos, autônomos e participativos. Eles orientam sobre o que e como ensinar. Foram elaborados, procurando, de um lado, respeitar as diversidades regionais, culturais, políticas existentes no país e, de outro, considerar a necessidade de construir referências nacionais comuns ao processo educativo em todas as regiões brasileiras. Com isso, pretende-se criar condições, nas escolas, que permitam aos jovens ter acesso ao conjunto de conhecimentos socialmente elaborados e reconhecidos como necessários ao exercício da cidadania.

${ }^{\ddagger}$ Resolução CNE/CEB n. 1 - de 3 de abril de 2002. A instituição das Diretrizes resulta das reivindicações históricas e mais acentuadas na última década, por parte das organizações e movimentos sociais que lutam por educação de qualidade social para todos os povos que vivem no e do campo, com identidades diversas, tais como, Pequenos Agricultores, Sem Terra, Povos da Floresta, Pescadores, Quilombolas, Ribeirinhos, Extrativistas, Assalariados Rurais.
} 
Finalidades, fontes de informação, procedimentos de trabalho e resultados distintos são motivos suficientes para considerar a distinção entre esses saberes históricos, como já vem sendo feito há mais de uma década por estudiosos do ensino de História ao redor do mundo, principalmente, porque o conceito de consciência histórica ajuda a perceber a presença de muitos outros saberes históricos além destes dois. (CERRI, 2001, p. 108).

É recorrente a ideia da importância, nos currículos escolares, de uma adequada educação cívica, baseada no desenvolvimento das capacidades intelectuais e dos valores éticos, morais e humanistas por meio dos quais configurariam as chamadas "consciências históricas". Mas, afinal, o que se entende por consciência histórica?

Para Schmidt e Garcia (2005), a consciência histórica funciona como um modo específico de orientação nas situações reais da vida presente, tendo como função específica ajudar-nos a compreender a realidade passada para compreender a realidade presente. De acordo com Cerri (2001), é um engano argumentar que o conceito de consciência histórica seja comum a todos que se utilizam da expressão. Pelo contrário, às vezes, ele se refere a realidades diferentes ou, até mesmo, excludentes.

Segundo Pais (1999), o estudo das formas de consciência histórica é uma forma de conhecimento que nos possibilita descobrir como os indivíduos vivem com os "fantasmas" do passado e, ao mesmo tempo, os utilizam como forma de conhecimento. A consciência histórica reporta-se ao passado, mas não a um qualquer passado. Não é um passado reificado, inerte, esquecido. Para o autor, a consciência histórica é a convocação permanente do passado ao presente.

Consciência histórica é um fenômeno próprio da existência humana ou característica específica de uma parcela da humanidade? É uma meta a ser alcançada? Mesmo com diferentes formações e espaços de exercício da atividade intelectual distintos, Hellen e Rusen aproximam-se no conceito de consciência histórica. Ambos enfatizam que a consciência histórica não é uma meta, mas uma das condições da existência do pensamento. Ela não está restrita a um determinado período da história, nem a certas regiões do planeta, nem a determinadas classes sociais ou a indivíduos mais ou menos preparados para a reflexão histórica ou social geral.

Para Heller (1993), a consciência histórica é inerente ao estar humano no mundo e é composta de diversos estágios. Rusen (2001) acentua que o ser humano tem de agir intencionalmente, e só pode agir no mundo se interpretá-lo a si mesmo de acordo com as intenções de sua atuação e de sua paixão.

Dessa forma, a consciência histórica não é algo que os homens possam ter ou não, ela é algo universalmente humano, devido à intencionalidade da vida prática do ser humano. É um fenômeno vital, imediatamente ligado com a prática. Para Rusen (2001), a consciência histórica é
A suma das operações mentais com as quais os homens interpretam sua experiência da evolução temporal de seu mundo e de si mesmos, de forma tal que possam orientar, intencionalmente, sua vida prática no tempo [...], o modo pelo qual a relação dinâmica entre experiência do tempo e intenção no tempo se realiza no processo da vida humana. (RUSEN, 2001, p. 57).

Segundo Rusen (1992), a forma linguística na qual a consciência histórica realiza sua função é a de orientar e narrar. Toda narrativa está marcada pela intenção básica do narrador e de seu público de não se perderem nas mudanças de si mesmos e 
de seu mundo, mas de manterem-se seguros e firmes no fluxo do tempo. Pela narrativa, é possível representar o passado de maneira clara e descritiva, que, na atualidade, se converta em algo compreensível, dessa forma, a experiência vital adquire perspectivas de futuro sólidas.

Ainda de acordo com o autor, a competência narrativa pode ser definida como uma habilidade da consciência humana em levar adiante procedimentos que dão sentido ao passado, permitindo uma orientação temporal na vida prática presente por meio da recordação da realidade passada. A consciência histórica se caracteriza pela competência de experiência, que supõe uma habilidade para ter experiências temporais. Implica a capacidade de aprender a olhar o passado e a resgatar sua qualidade temporal, diferenciando-o do presente. Segundo Fonseca (2006), a experiência não deve ser pensada descolada da vida cotidiana, da cultura, das relações sociais, nem dos valores. "Ex-per-iência significa por para fora e passar através." (LAROSSA, 1996 apud FONSECA, 2006). A categoria experiência permite compreender as relações entre o conhecimento e a vida humana.

Outra característica da consciência histórica, segundo Rusen (1992), é a competência de interpretação. Essa competência é a habilidade de diminuir a distância entre o passado, o presente e o futuro por meio de uma concepção de um todo temporal significante que abarque todas as dimensões do tempo. A competência de orientação supõe ser capaz de utilizar o todo temporal, com seu conteúdo de experiência, para os propósitos de orientação da vida. Implica guiar a ação por meio das noções de mudanças temporais, articulando identidade humana com conhecimento histórico, tecendo identidade na trama concreta do conhecimento histórico.

Um pressuposto da consciência histórica é que o indivíduo existe em grupo, sendo assim, a percepção e o significado do tempo são coletivos. As dimensões do passado - de onde viemos -, do presente - quem somos - e do futuro - para onde vamos - , são elementos de ligação que se estabelecem entre os indivíduos. Segundo Cerri (2001), essa ligação é que pode ser chamada de identidade, que se caracteriza como um conjunto de ideias que tornam possível uma delimitação básica para o pensamento humano: nós e eles, pertencer ou não ao grupo.

Comungamos com Pais (1999), ao afirmar que, sem consciência histórica do passado, não perceberíamos quem somos. A dimensão identitária emerge no terreno das memórias históricas partilhadas. O sentimento de identidade, entendido no sentido de imagem de si, para si e para os outros, está associado à consciência histórica, que, de acordo com o autor, é a forma de nos sentirmos em outros que nos são próximos, que antecipam a nossa existência, que, por sua vez, antecipará a dos outros.

A consciência histórica é fruto de múltiplas representações. Segundo Pais (1999), a representação não é repetição, é mediação incitadora e motivante. É uma reintrodução de sentido, um retorno do sentido. Devolve o gosto pela apresentação no sentido da presença construída, daí, sua capacidade analógica irredutível. " $A$ consciência histórica é uma construção simbólica, do mesmo modo que a identidade comporta também um processo de apropriação simbólica do real" (PAIS, 1999, p. 2). É possível afirmar que experiência, representação, identidade, memória, sentido e vida prática humana são elementos que constituem a consciência histórica.

Outro conceito fundamental para compreender a formação da consciência histórica é o da concepção de tempo. De acordo com Pagés e Santisteban (2008), é necessário revisar essa concepção, buscando as relações entre tempo e espaço, dessa 
forma, é possível ajudar a formar a consciência histórica como consciência temporal, considerando o futuro como o objetivo último do estudo da História. $\mathrm{O}$ autor assevera que a consciência histórica se configura por meio das relações que estabelecemos entre o passado, o presente e o futuro, e é essencial na educação para a cidadania.

Com o desejo de construir uma teoria do desenvolvimento ontogenético da consciência histórica, Rusen (1992) a dividiu em quatro tipos: tradicional, exemplar, crítica e genética. Segundo o autor, existem seis elementos e fatores da consciência histórica os quais podem identificar esses tipos: 1) seu conteúdo, ou seja, a experiência dominante do tempo trazida desde o passado; 2) as formas de identificação histórica, ou as formas de temporalidade histórica; 3) o modo de orientação externa, especialmente, as formas comunicativas da vida social; 4) o modo de orientação interna, particularmente, referente à identidade histórica; 5) a relação da orientação histórica concernente a valores morais; 6) sua relação com a razão moral.

Esses quatro tipos de consciência histórica podem ser definidos da seguinte maneira: tradicional (a totalidade temporal é apresentada como continuidade dos modelos de vida e da cultura do passado); exemplar (as experiências do passado são casos que representam e personificam regras gerais da mudança temporal e da conduta humana); crítica (permite formular pontos de vista históricos, por negação de outras posições); e genética (diferentes pontos de vista podem ser aceitos, porque se articulam em uma perspectiva mais ampla de mudança temporal, e a vida social é vista em toda sua complexidade).

Assim, podemos assegurar que os dois primeiros tipos de consciência histórica supõem uma atitude passiva de quem recebe o conhecimento histórico como se este se desse fora dos sujeitos. De forma diferente, nos modos crítico e genético, os sujeitos que participam do processo de ensino e aprendizagem da história convertem-se em participantes ativos e produtivos desse processo. Segundo Rusen (1992), os modos tradicionais e exemplares estão bastante estendidos e pode-se falar com frequência que os modos críticos e genéticos são mais raros. As formas tradicionais de consciência histórica são mais fáceis de aprender e, de acordo com Rusen (1992), a forma exemplar domina a maior parte dos currículos de história, e as competências críticas e genéticas requerem um esforço maior por parte de estudantes e professores.

Concordamos com os estudos de Rusen (1992), que nos levam a compreender que os estudantes precisam desenvolver estruturas históricas úteis para que se orientem no tempo. Dessa forma, o ensino de História tem a função de orientar e de compreender da disciplina. Um questionamento continua recorrente e instiga investigações: o ensino de História, ao longo da história, cumpriu essa função?

\section{As finalidades do ensino de História na história da disciplina}

A história pode ser compreendida como obra humana, como movimento, cuja síntese escapa ao controle de seus agentes, mesmo aos coletivamente organizados. Segundo Marx (1961), os homens fazem sua própria história não como querem, não a fazem sob circunstância de sua escolha e, sim, sob aqueles que se defrontam diretamente, ligadas e transmitidas pelo passado. Dessa forma, é possível perceber a importância do passado na vida prática do ser humano. Pensando assim, um questionamento permanece inquietante: qual a finalidade do ensino de História?

Com o intuito de revisitar a história do ensino de História recorremos a autores 
como Fonseca (2001 e 2005) e Bittencourt (2004). Por esse estudo, podemos caracterizar o ensino de História a partir de dois momentos. O primeiro teve início na primeira metade do século XIX, com sua introdução no currículo escolar. Pósindependência do Brasil, a preocupação era criar uma "genealogia da nação", para tanto, elaborou-se uma "história nacional", baseada em uma matriz europeia. O segundo momento ocorreu a partir das décadas de 1930 e 1940, orientado por uma política nacionalista e desenvolvimentista. Como área escolar obrigatória o ensino de História surgiu com a criação do Colégio Pedro II em 1937, inspirado no modelo francês. Segundo os PCN do ensino de História, o objetivo era a formação de cidadãos proprietários e escravistas.

De acordo com Bittencourt (2004), desde o início da organização do sistema escolar, a proposta de ensino de História voltava-se para uma formação moral e cívica. Os conteúdos passaram a ser elaborados para construir uma ideia de nação associada à de pátria, integradas como eixos indissolúveis. Deveriam inculcar determinados valores para a preservação da ordem, da obediência à hierarquia, de modo que o país pudesse chegar ao progresso, modernizando-se consoante com o modelo dos países europeus.

O conceito de cidadania, criado com o auxílio do ensino de História, serviria para colocar cada indivíduo no seu lugar, ou seja, caberia ao político cuidar da política, e ao trabalhador restava votar e trabalhar dentro da ordem institucional. Em relação à História do Brasil, os acontecimentos históricos ensinados iniciavam com a história portuguesa - a sucessão de reis em Portugal e seus respectivos governos - e, na sequência , era introduzida a história do Brasil, abordando temas como as capitanias hereditárias, os governos gerais, as invasões estrangeiras ameaçando a integridade nacional. Os conteúdos culminavam com os "grandes eventos" levados a efeito pelos "grandes homens". Esse ensino não situava os homens comuns como sujeitos da história.

Nesse sentido, privilegiava-se a formação da consciência histórica nos moldes tradicionais. Uma identidade centrada, fixa, unificada. Uma identidade de pertença, formando um bloco. Cristalizada. Esse tipo de identidade assinala-se em frases como: "sou brasileiro". Desconsidera as subjetividades, as singularidades e as diversidades em ser brasileiro. Sufocava as outras identidades em nome da "ordem".

No final do século XIX, com a Proclamação da República, passou a ser função da escola denunciar os atrasos impostos pela monarquia, inspirados nas ideias positivistas, a educação escolar deveria regenerar os indivíduos e a própria nação, e, dessa forma, colocaria o país na rota do progresso e da civilização. Sendo assim, o ensino de História passou a ocupar, no currículo, um duplo papel: civilizatório e patriótico. Deveria modelar um novo tipo de trabalhador, o cidadão patriótico. A História Nacional identificava-se com a História Pátria, cuja finalidade era integrar o povo brasileiro à moderna civilização ocidental, reforçando a visão linear, determinista, e eurocêntrica da história. Seus conteúdos deveriam enfatizar as tradições de um passado homogêneo de lutas, de feitos gloriosos de personagens identificados com ideais republicanos.

No início do século XX, apesar das sucessivas reformas dos governos republicanos, pouco foi feito para alterar a escola pública. Contudo o período constituiuse em um momento de fortalecimento de debates sobre os problemas educacionais. Foram criadas propostas alternativas ao modelo oficial, porém sofreram repressão por parte do governo republicano, como, por exemplo, as escolas anarquistas, que, segundo 
Bittencourt (2004), apresentavam currículos e métodos próprios, nos quais o ensino de História deixava de enfocar a hierarquia entre os povos para identificar-se com os momentos das lutas sociais.

Com a Reforma Francisco Campos, a partir de 1930, acentuaram-se o fortalecimento do poder central do Estado e o controle do ensino. Nesse contexto, o ensino de História privilegiava unicamente, no caso da história do Brasil, a continuidade da história da Europa ocidental. A periodização obedecia a uma cronologia política marcada por tempos uniformes, tempo vetorial, tempo flecha, sucessivos e regulares, sem rupturas ou descontinuidades. Consolidava-se a ideia de tempo único, contínuo, homogêneo e irreversível. O ensino de História permanecia como instrumento de desenvolvimento do patriotismo e da unidade étnica, administrativa, territorial e cultural da nação.

Com o movimento escolanovista no Brasil, destacaram-se propostas de abordagem diferenciada, porém, de acordo com Bittencourt (2004), nas salas de aula, permaneciam as práticas que exigiam dos alunos as lições de "cor", com datas e nomes de personagens considerados os mais significativos da história. Com as reformas conduzidas pelo ministro Gustavo Capanema, a partir de 1942, o ensino de História tinha como tarefa enfatizar o ensino patriótico, capaz de criar, nas novas gerações, a consciência da responsabilidade frente aos valores maiores da pátria, a sua independência, a sua ordem e o seu destino.

No contexto da democratização do Brasil, pós Segunda Guerra Mundial, o ensino de História tornou-se uma disciplina significativa na formação de uma cidadania para a paz. A proposta era de um ensino revestido de um conteúdo mais humanístico e pacifista, voltando-se ao estudo dos processos de desenvolvimento econômico das sociedades, bem como dos avanços tecnológicos, científicos e culturais.

Nos anos de 1950 e 1960, sob a inspiração do nacional-desenvolvimentismo, o ensino de História voltou-se para as temáticas econômicas. Enfatizou-se o estudo dos ciclos econômicos, sua sucessão linear no tempo (cana-de-açúcar, mineração, café e industrialização). A ordenação linear e sucessiva indicava que o desenvolvimento só seria alcançado com a industrialização. Ficava subentendido que o urbano era $o$ sinônimo de progresso e o rural era o atraso.

O período que se estendeu da Segunda Guerra Mundial até o final dos anos de 1970 caracterizou-se por momentos significativos na implementação dos Estudos Sociais. Sob influência norte-americana e de uma difusa concepção tecnocrática, no contexto da Guerra Fria, desvalorizaram-se as áreas de Humanas em favor de um ensino técnico, para formação da mão-de-obra da indústria crescente. Com o golpe militar em março de 1964, proliferaram os cursos de Licenciatura Curta. A partir da LDB 5692/71, ao lado da Educação Moral e Cívica (EMC) e da Organização Social e Política Brasileira (OSPB), os Estudos Sociais esvaziaram, diluíram e despolitizaram os conteúdos de História e Geografia. Foram valorizados os conteúdos e as abordagens de um nacionalismo de caráter ufanista, destinado a justificar o projeto nacional do governo militar após 1964.

Com os Estudos Socais, para compreender a realidade social, o aluno deveria dominar, em princípio, entre outras noções, a de tempo histórico. Mas o desenvolvimento dessa noção limitava-se a atividades do tempo cronológico e de sucessão: datações, calendário e ordenação temporal, passado-presente-futuro. Caracterizava-se por uma linha do tempo, amarrada a uma visão linear. O agente 
histórico, segundo Bittencourt (2004), continuava sendo o Estado, sendo ele responsável pela transformação da natureza, pelos avanços tecnológicos e pelo bem estar da população. Prevalecia a origem e a repetição de um modelo cultural e de vida obrigatório. Dessa forma, podemos afirmar que os saberes históricos possibilitavam uma consciência histórica tradicional e exemplar.

No decorrer dos anos de 1970 e 1980, as lutas profissionais, desde a sala de aula até a universidade, ganharam maior expressão com o crescimento das associações de historiadores e geógrafos, abrindo possibilidades da volta do ensino de História e de Geografia aos currículos escolares e a extinção dos cursos de Licenciatura de Estudos Socais.

O caminho da democratização dos anos de 1980 foi caracterizado por uma série de transformações. O processo de migração se tornou intenso, tanto do meio rural para as cidades como também entre os estados. $\mathrm{O}$ espaço escolar tornou-se cada vez mais multicultural. As tecnologias de comunicação, principalmente, o rádio e a televisão, expandiram-se consideravelmente. Essa nova realidade não poderia ser ignorada pela escola. O currículo real forçava mudanças no currículo formal. As propostas curriculares passaram a ser influenciadas também pelo debate entre as diversas tendências historiográficas. Temas ligados à história social, cultural e do cotidiano passaram a ser debatidos.

O debate gerou a reavaliação do ensino de História ilustrada pelas múltiplas abordagens históricas possíveis. Difundiram-se reflexões sobre o processo de ensino/ aprendizagem pelos quais os alunos passaram a ser considerados sujeitos de saberes, participantes ativos do processo de conhecimento. Os métodos tradicionais de ensino, como memorização e reprodução, passaram ser questionados.

Nesse contexto, especificamente em 1997, após longos debates, foram aprovados os Parâmetros Curriculares Nacionais (PCN). Quais as mudanças no ensino de História foram veiculadas nesse documento? Que tipo de consciência histórica pode ser formada sob influência dos PCN? É possível perceber a valorização, o respeito, o diálogo com as singularidades do ensino de História no meio rural? A preocupação de Rusen (2001), em perceber como dos feitos se faz a história, é instigadora e inspiradora. Mas, neste estudo, interessa-nos saber, além das questões pontuadas anteriormente, dentre os feitos da humanidade, quais os priorizados pelo PCN dos anos finais do ensino fundamental. Por que esses conteúdos e não outros? São essas questões a que buscamos responder na continuação desse texto.

\section{A proposta curricular do ensino de História, as Diretrizes Operacionais para Educação no Campo e a consciência histórica}

Entendemos o currículo como uma construção cultural, como um modo de organizar uma série de práticas educativas. $\mathrm{O}$ conhecimento corporificado no currículo não é algo fixo, mas um artefato social e histórico, sujeito a mudanças e flutuações. $O$ currículo deve ser percebido como um processo constituído de conflitos e lutas entre diferentes tradições e diferentes concepções sociais. A seleção e a organização do conhecimento escolar não podem ser vistas como escolhas inocentes, não são um processo lógico, mas social, no qual convivem, lado a lado, fatores epistemológicos e intelectuais.

O currículo não é constituído de conhecimentos válidos, mas de conhecimentos 
considerados socialmente válidos. Segundo Apple (1982), o currículo participa do processo de construção das identidades que dividem a esfera social, ajudando a produzir, entre outras, determinadas identidades raciais, sexuais e nacionais. Sendo assim, podemos argumentar que, nas discussões críticas sobre o currículo, evidenciamse análises que focalizam a produção de identidades sociais.

Ao longo da história da educação brasileira, os currículos escolares apontavam para a importância social do ensino de História. Uma das tradições da área foi a de contribuir para a construção da identidade, sendo esta entendida como a formação de um "cidadão patriótico", "homem civilizado" ou da "pessoa ajustada ao seu meio". De acordo com a proposta do ensino de História, registrada pelos PCN, é necessário repensar sobre o que se entende por identidade e qual a sua relevância para a sociedade brasileira contemporânea.

O que os alunos aprendem ou deixam de aprender vai muito além do que está prescrito nos documentos oficiais. Conforme Cerri (2001), os problemas e as potencialidades do ensino e a aprendizagem de história não estão restritos à relação professor-aluno na sala de aula, mas envolvem o meio em que o aluno e professor vivem, os conhecimentos e opiniões que circulam em sua família, na igreja ou noutras instituições que frequentam e nos meios de comunicação de massa a que têm acesso. Entretanto, como afirmamos anteriormente, interessa-nos analisar o que está explícito e implícito na proposta curricular - PCN - dos anos finais do ensino fundamental, documento que representa e legitima as decisões políticas para os sistemas de ensino no Brasil.

De acordo com os PCN, desde que a História ensinada foi incorporada no currículo escolar, tem-se mantido uma interlocução com o conhecimento histórico. $\mathrm{O}$ documento ressalta a importância de aprofundar e revelar as dimensões da vida cotidiana de trabalhadores, mulheres, crianças, grupos étnicos, velhos e jovens e de pesquisas que estudam práticas e valores relacionados às festas, à saúde, à doença, ao corpo, à sexualidade, à prisão, à educação, à cidade, ao campo, à natureza e à arte. Propõe a utilização das mais variadas fontes de pesquisas, como a documentação escrita oficial, textos, jornais, revistas, imagens, relatos orais, objetos e registros sonoros.

Os PCN defendem a afirmação de que as formas de estudar o passado são plurais. Ressaltam que a diversidade de temas e abordagens deve ser alimentada e fundamentada pelo diálogo da História com outras áreas do conhecimento das Ciências Humanas, como a Filosofia, a Economia, a Política, a Geografia, a Sociologia, a Psicologia, a Antropologia, a Arqueologia, a Crítica Literária, a Linguística e a Arte. Reforçam que as atitudes do professor-pesquisador sejam de identificar, relacionar, interpretar o passado como expressões de vivências e de modos de pensar contraditórios de uma realidade social e cultural representadas.

É possível perceber que o documento está mais "antenado" com a complexidade do conceito de identidades. Comungamos com Bauman (2005) e Hall (2005), ao afirmarem que o que se tem de concreto é um sujeito fragmentado, cambiante, deslocado, no qual estão em conflitos várias identidades, algumas, inclusive, antagônicas. As identidades do indivíduo são organizadas em torno de imagens dinâmicas de exploração e transformação de diferentes realidades. Concordamos com Lévy (2007), ao asseverar que o ser humano volta a tornar-se nômade, pluraliza sua identidade, explora mundos heterogêneos e múltiplos, em devir pensantes. Defendemos a possibilidade de avançar na proposta dos PCN e trabalhar os saberes históricos 
escolares na perspectiva de permitir alunos e professores fluírem, mesclarem-se, valorizarem-se, dilatarem-se e trocaram-se. Aceitarem distintos pontos de vista em uma perspectiva que abarque o desenvolvimento comum. Dessa forma, avançar na formação de uma consciência histórica crítica e genética.

Quanto à noção de tempo, em vez de percebê-lo como contínuo e evolutivo, igual e único para toda a humanidade, valoriza-se o esforço de perceber a descontinuidade das mudanças. Enfatiza-se a importância de refletir sobre os diferentes níveis e ritmos de durações temporais. Durações relacionadas à percepção dos intervalos das mudanças ou das permanências nas vivências humanas. Essa concepção de tempo é baseada nos estudos de Fernand Braudel. Segundo Bourdé (s.d.), Braudel situa a história em três escalões: à superfície, uma história dos acontecimentos, que se inscreve no tempo curto; a meia encosta, uma história conjuntural, que segue um ritmo mais lento; em profundidade, uma história estrutural, de longa duração, que põe em causa séculos.

De acordo com Páges e Santisteban (2008), a compreensão da temporalidade é fundamental para uma educação democrática. Destaca elementos como: entender o presente, tomar decisões e pensar o futuro. Consideramos uma grande contribuição do autor no que diz respeito a aprendizagem do futuro. $\mathrm{O}$ autor afirma que as aproximações ao estudo do futuro podem situar-se em três âmbitos:

a) las creencias, que han dado lugar a la escatologia y a apocalíptica, también al milenarismo y al mesianismo, así como a los mitos del fin del mundo; b) las ideologias, que han producido las utopias, las cuales han jugado un papel muy importante en la configuración del pensamiento social contemporáneo; c) la ciencia, que utiliza la prospectiva para analizar la posible evolución de los acontecimientos en futuro, de tal manera que esta actividad se há convertido en uma parte esencial de la ciencia y de las ciencias sociales, por ejemplo en la economia o en la política. Este tercer âmbito del futuro es el que más nos interesa desde la enseñanza. (PAGÉS; SANTISTEBAN, 2008, p. 6-7).

Acreditamos que essa noção de tempo, defendida por Páges e Santisteban (2008), avança em relação ao que propõem os PCN, comungamos com o autor ao afirmar que no ensino de História, devemos conectar o estudo do passado com a prospectiva no futuro. $\mathrm{O}$ ensino de História deve apoiar-se nos pré-requisitos temporais necessários para introduzir o aluno na experiência histórica e deve ser ensinado desde os primeiros anos de escolaridade.

De acordo com os PCN, espera-se que, ao longo do Ensino Fundamental, os alunos, gradativamente, possam ampliar a compreensão de sua realidade, especialmente, confrontando-a e relacionando-a com outras realidades históricas. Assim, supõe-se que os professores possam fazer suas escolhas, estabelecer critérios, selecionar saberes e orientar suas ações. Nesse sentido, os alunos deverão ser capazes de:

1) Identificar relações sociais no seu próprio grupo de convívio, na localidade, na região e no país, e outras manifestações estabelecidas em outros tempos e espaços;

2) situar acontecimentos históricos e localizá-los em uma multiplicidade de tempos;

3) Reconhecer que o conhecimento histórico é parte de um conhecimento interdisciplinar;

4) compreender que as histórias individuais são partes integrantes de histórias coletivas; 
5) conhecer e respeitar o modo de vida de diferentes grupos, em diversos tempos e espaços, em suas manifestações culturais, econômicas, políticas e sociais, reconhecendo semelhanças e diferenças entre eles, continuidades e descontinuidades, conflitos e contradições sociais.

6) Questionar sua realidade, identificando problemas e possíveis soluções, conhecendo formas político-institucionais e organizações da sociedade civil que possibilitem modos de atuação.

7) Dominar procedimentos de pesquisa escolar e de produção de texto, aprendendo a observar e colher informações de diferentes paisagens e registros escritos, iconográficos, sonoros e materiais.

8) Valorizar o patrimônio sociocultural e respeitar a diversidade social, considerando-os critérios éticos.

9) Valorizar o direito de cidadania dos indivíduos, dos grupos e dos povos como condição de efetivo fortalecimento da democracia, mantendo-se o respeito às diferenças e a luta contra desigualdade (BRASIL, 1997, p. 43).

A análise dos Parâmetros Curriculares Nacionais evidencia uma preocupação do Estado com a inclusão da diversidade cultural no currículo de História, com a formação para a cidadania e com a intenção de integrar o ensino ao cotidiano do aluno. Dessa forma, acreditamos na possibilidade de considerar as especificidades da educação escolar no meio rural, sem desconsiderar os saberes que devem ser comuns a todos os estudantes. Segundo as Diretrizes Operacionais para a Educação básica nas Escolas do Campo, a identidade da escola do campo é definida da seguinte maneira:

Art. 2 - Parágrafo único. A identidade da escola do campo é definida pela sua vinculação às questões inerentes à sua realidade ancorando-se na temporalidade e saberes próprios dos estudantes, na memória coletiva que sinaliza futuros, na rede de ciência e tecnologia disponível na sociedade e nos movimentos sociais em defesa de projetos que associem as soluções exigidas por essas questões à qualidade social da vida coletiva do País. (BRASIL, 2002, p.37).

De acordo com o documento, os saberes docentes necessários aos professores das escolas devem levar em conta as especificidades do meio rural:

Art. 13. Os sistemas de ensino, além dos princípios e diretrizes que orientam a Educação Básica no País, observarão, no processo de normatização complementar da formação de professores para o exercício da docência nas escolas do campo, os seguintes componentes:

I - estudos a respeito da diversidade e o efetivo protagonismo das crianças, dos jovens e dos adultos do campo na construção da qualidade social da vida individual e coletiva, da região, do País e do mundo;

II - propostas pedagógicas que valorizem, na organização do ensino, a diversidade cultural e os processos de interação e transformação do campo, a gestão democrática, o acesso ao avanço científico e tecnológico e respectivas contribuições para a melhoria das condições de vida e a fidelidade aos princípios éticos que norteiam a convivência solidária e colaborativa nas sociedades democráticas. (BRASIL, 2002, p. 41).

O diálogo entre os PCN de ensino de História e as Diretrizes Operacionais da Educação Básica nas Escolas do Campo possibilita-nos uma reflexão sobre que tipo de consciência histórica é possível formar nos jovens estudantes de escola no meio rural. Para Rusen (2001), a consciência histórica é a realidade por meio da qual se pode entender o que é a História como ciência e por que ela é necessária. Acreditamos que o 
professor de História de escolas rurais compromissado com a realidade em que atua, aprofundando seus estudos de forma crítico- reflexiva sobre os PCN, auxilie seus alunos a construírem uma consciência histórico-crítica, proporcionando atividades que levem os alunos ao entendimento de uma narrativa construída, procurando nela o sentido que o autor quis dar a ela e sensibilizando-o, com as suas intenções e pressupostos.

\section{Considerações finais}

O estudo sobre os PCN do ensino de História nos revelou indícios de que estão ancorados em vertentes historiográficas que entendem a história como estudo da experiência humana no tempo. A história estuda a vida de todos os homens e mulheres, com a preocupação de recuperar o sentido de experiências individuais e coletivas. Os documentos apontam que este deve ser um dos principais critérios para a seleção de conteúdos e sua organização em temas a serem ensinados com o objetivo de contribuir para a formação de consciências individuais e coletivas numa perspectiva crítica. As Diretrizes Operacionais para a Educação básica nas Escolas do Campo reforçam a necessidade de considerar os saberes dos jovens e a relação tempo e espaço no processo ensino/aprendizagem.

Os documentos apontam para a necessidade de reformular os conteúdos, priorizando a construção de problematizações históricas. Sugerem a apreensão de várias histórias lidas a partir de distintos sujeitos históricos, das histórias silenciadas. Reforçam a importância de recuperar a vivência pessoal e coletiva dos estudantes. $\mathrm{Na}$ escolha dos conteúdos, a proposta dos PCN é propiciar aos alunos o dimensionamento de si mesmos e de outros indivíduos e grupos em temporalidades históricas. Os conteúdos devem sensibilizar e fundamentar a compreensão de que os problemas atuais e cotidianos não podem ser explicados unicamente a partir dos acontecimentos restritos ao presente. Requerem questionamentos ao passado, análises e identificação de relações entre vivências sociais no tempo.

$\mathrm{O}$ estudo nos revelou que os PCN trazem um avanço considerável nas finalidades do ensino de História. A possibilidade de levar aos alunos à passagem de uma consciência histórica tradicional e exemplar para uma consciência história crítica e genética está dada nos documentos. Contudo não são suficientes para que se efetivem na prática. Defendemos a necessidade de pesquisas que registrem os saberes e os fazeres dos professores de História. De políticas públicas que possibilitem a formação continuada e contínua dos professores que atuam no meio rural, e, assim, estimular estudos críticos sobre os documentos oficiais.

Acreditamos na importância de escutar, integrar e restituir a diversidade. Um ensino de História que auxilie na construção das identidades de estudantes e professores. Dessa forma, é possível uma consciência histórica crítica e genética. É fundamental que o ensino de História nos auxilie na construção de uma democracia em tempo real. Para isso, é imperativo considerar o que Lévy (2007) nos ensina: 1) escutar os outros coralistas; 2) cantar de modo diferenciado; 3) encontrar uma coexistência harmônica entre sua própria voz e a dos outros, ou seja, melhorar o efeito do conjunto.

A relevância do conhecimento histórico, ou seja, do saber ensinado, encontrado nos indícios dos documentos analisados, se confrontados com a experiência cultural de estudantes e professores, pode permitir que esses sujeitos se apropriem e/ou construam maneiras pelas quais os saberes podem ser ensinados e aprendidos. Nesse sentido, é 
possível pensar em uma contribuição mais efetiva do ensino de História em escolas no meio rural, na transformação da sociedade.

\section{Referências bibliográficas}

APPPLE, M.W. Ideologia e currículo. São Paulo: Brasiliense, 1982.

BRASIL. Ministério da Educação. Diretrizes operacionais para a educação básica nas escolas do campo. Brasília, DF, 2002.

. Proposta curricular de história: Ensino Fundamental, Secretaria de Educação de Minas Gerais, 1997.

BAUMAN, Zygmunt. Identidade. Rio de Janeiro: Jorge Zahar Editora, 2005.

BOURDIÉ, Guy e MARTIN, Hervé. As escolas históricas. S.I.C., Portugal: Publicações Europa América, s.d.

CERRI, Luis Fernando. Os conceitos de consciência histórica e os desafios da didática da História. Revista da História Regional, 6(2). p. 93-112, Inverno, 2001.

FONSECA, Selva Guimarães. Aprender a contar, a ouvir, a viver: as narrativas como processo de formação. In: VEIGA, Ilma Passos (org).Técnicas de ensino: novos tempos, novas configurações. Campinas, S. P.: Papirus, 2006.

. Caminhos da história ensinada. Campinas SP: Papirus, 2001.

. Didática e Prática de Ensino de História. 3. ed. Campinas SP: Papirus, 2005.

HALL, Stuart. A identidade cultural na pós-modernidade. Tradução Tomaz Tadeu da Silva e Guaracira Lopes Louro. 10. ed. Rio de Janeiro: DP\&A, 2005.

HELLER, Agnes. O cotidiano e a história. Tradução de Carlos N. Coutinho e Leandro Konder. 4. ed. Rio de Janeiro: Paz e Terra, 1992.

. Uma teoria da história. Rio de Janeiro: Civilização Brasileira, 2007.

LÉVY, Pierre. A inteligência coletiva. Tradução Luiz Paulo Rouane. 5. ed. São Paulo: Edição Loyola, 2007.

MARX, Karl.O Dezoito Brumário de Luis Bonaparte. Rio de Janeiro: Vitória, 1961. (K. Marx / F. Engels - Obras escolhidas, volume 1).

PAGÉS, Jean; SANTISTEBAN, Antoni Fernández. Cambios y continuaidades: aprender la temporalidad histórica. In: JARA, M. A. (coord.): Enseñanza de la Historia. Debates y Propuestas. Argentina: EDUCO Editorial de la Universidad nacional del Comahue, 2008. p.91-127.

PAIS, José Machado. Consciência Histórica e Identidades: os Jovens Portugueses num Contexto Europeu. Celta Editora Lda, 1999.

RUSEN, Jorn. El desarrolo de la competencia narrativa em el aprendizage histórico. Uma hipotese ontogenética relativa a consciencia moral. Propuesta educativa, n. 7,

FLASCSO, p. 27-36, 1992. 


\section{INTERFACES DA EDUCAÇÃO}

RUSEN, Jorn. Razão histórica - teoria da história: fundamentos da ciência história. Tradução de Estevão de Rezende Martins. Brasília: Editora Universidade. Brasília: Editora Universidade Brasília, 2001.

SCHMIDT, Maria Auxiliadora e GARCIA, Tânia Maria F. Braga. A formação da consciência histórica de alunos e professores e o cotidiano em aulas de História. Cadernos Cedes, Campinas, v. 25, n. 67, p. 297-308, set./dez., 2005.

ZAMBONI, Ernesta. Projeto Pedagógico dos Parâmetros Curriculares Nacionais: Identidade Nacional e Consciência Histórica. Cadernos Cedes, Campinas, v. 23, n. 61, p. 367-377, dezembro, 2003. 